\title{
KNOWLEDGE AND ATTITUDE ON DIABETES MELLITUS AMONG RESIDENTS OF JOS METROPOLIS, PLATEAU STATE, NIGERIA
}

\author{
Dr. Elendu C. Onwuchekwa ${ }^{1^{*}}$, Prof. L. N. Chigbu², Dr. Daniel M. Gimbason ${ }^{3}$, \\ Dr. Uzochukwu G. Ekeleme ${ }^{4}$ and Onuigbo C. Martin ${ }^{5}$ \\ ${ }^{1}$ Department of Public Health, Abia State University, Uturu \\ ${ }^{2}$ Department of Medical Laboratory, Abia State University, Uturu \\ ${ }^{3}$ Coordinator Community Health Officers Training Programme (CHOTP), Bingham \\ University Teaching Hospital, Jos \\ ${ }^{4}$ Department of Public Health, Federal University of Technology, Owerri \\ ${ }^{5}$ Department of Microbiology, Gregory University Uturu
}

*Corresponding author’s email: drelenduco@gmail.com, uzochukwugods@gmail.com

Cite this article:

Elendu C.O., Chigbu L.N. , Daniel M.G., Uzochukwu G.E., Onuigbo C.M. (2021), Knowledge and Attitude on Diabetes Mellitus Among Residents of Jos Metropolis, Plateau State, Nigeria. African Journal of Health, Nursing and Midwifery 4(2), 26-37. DOI: 10.52589/AJHNMNMM9C2KO.

\section{Manuscript History}

Received: 1 April 2021

Accepted: 22 April 2021

Published: 27 April 2021

Copyright $\odot 2020$ The Author(s). This is an Open Access article distributed under the terms of Creative Commons AttributionNonCommercial-NoDerivatives 4.0 International (CC BY-NC-ND 4.0 ), which permits anyone to share, use, reproduce and redistribute in any medium, provided the original author and source are credited.
ABSTRACT: Introduction: Diabetes is a chronic condition that can affect the entire body. There is no doubt that the prevalence of diabetes mellitus has been increasing worldwide. This study investigated the knowledge and attitude on diabetes mellitus (DM) among residents of Jos metropolis, Plateau State, Nigeria. Five research objectives were outlined to identify the causes of DM in Jos metropolis, to examine the effects of diabetes mellitus in Jos, to interrogate the level of knowledge of diabetes in Jos, and proffer recommendation and suggestions on how the challenges of diabetes can be addressed. Methodology: Data were collected both qualitatively and quantitatively using questionnaire, and Focus Group Discussion (FGD). 420 respondents were sampled using multi stage and simple random sampling technique, the data analyzed was based on 393 questionnaires retrieved from the field and presented according to the study objectives. The key informants were purposely selected for the Focus Group Discussion. An FGD guide was used for the research. Results: $94.8 \%$ of the respondents agreed that they were knowledgeable of diabetes mellitus and have ideas of the possible causes of diabetes. Majority of the respondents (60.7\%) agreed that diabetes is a genetic disease, some indicated that it is a nutritional disease. 247 (62.8\%) indicated that people between the ages of forty to sixty years are more likely to contract diabetes, $28(7.1 \%)$ of the respondents indicated that aged people of seventy years and above are more likely to be diabetic. While 89 (22.6\%) of the respondents indicated that people of all age categories can suffer diabetes mellitus. Conclusion: Factors militating against the effective treatment of diabetes in Jos metropolis are stigmatization of diabetic patients, poor access to healthcare facilities and low level of awareness by residents on $D M$. The study established that when people are knowledgeable of the causes, effects and remedy of diabetes mellitus, the rate of the disease will be reduced to the lowest minimum. The study recommends that there should be awareness among the health workers and training health professionals on nutrition and diabetes as may enhance quality healthcare delivery in the nearest future.

KEYWORDS: Diabetes Mellitus, Knowledge, Attitude, Jos Metropolis, Stigmatization 
ISSN: 2689-9418

Volume 4, Issue 2, 2021 (pp. 26-37)

www.abjournals.org

\section{INTRODUCTION}

The prevalence of diabetes mellitus has been increasing worldwide, reaching epidemic proportions in many countries including Nigeria (Unachukwu et al., 2011). Several trials over the years demonstrate that lifestyle modifications like weight loss and physical activities reduce the chances of diabetes mellitus. Diabetes as a metabolic disorder occurs when the metabolic agents including insulin, are for example, either absent or deficient or are produced in inappropriate forms that the blood sugar is prevented from entering into the body cells either for storage or energy generation. Langenberg et al. (2014) further stated that a family history of diabetes or heart disease also gives an increased risk of developing the disease, which further is elevated by lifestyle factors such as smoking and obesity.

Deaths related to diabetes in Nigeria in 2013 were estimated to be 105,091 cases. Nigeria has the highest burden of diabetes in Africa, followed by South Africa with 2.6 million cases, Ethiopia 1.9 million, and Tanzania 1.7 million. The global prevalence of diabetes by 2017 estimates is 382 million cases, a large population of it (175 million) undiagnosed, and the global prevalence about $8.3 \%$. More than half of the deaths due to diabetes occur in people less than 60 years old. It has been estimated that the number of diabetes sufferers in the world will double from the current value of about 190 million to 325 million during the next years (WHO Annual report, 2014). The World Health Organization (WHO, 2012) estimated that diabetes mellitus resulted in 1.5million deaths in 2012 making it the eighth leading cause of death globally. However, another 2.2 million deaths worldwide were attributed to high blood glucose (hyperglycemia) and the increase rate of cardio-vascular diseases and other associated complicated conditions (such as kidney failure), which often leads to premature death and are often listed as the underlying cause of death (WHO Annual report, 2014).

The amount and type of food consumed is a fundamental determinant of human health. Diet constitutes a crucial aspect of the overall management of diabetes, which may involve diet alone, diet with oral hypoglycemic drugs, or diet with insulin (Park et al., 2003). Diet is individualized depending on age, weight, gender, health condition, and occupation. In addition, when diabetics eat glucose in foods such as breads, cereals, fruit and starchy vegetables, legumes, milk, yoghurt and sweets, it cannot be converted into energy, as it would be in a nondiabetic patient. Instead of being turned into energy, the glucose stays in the blood that is why blood glucose levels (or glycemia) are higher in people with diabetes (Ntui et al., 2006). Therefore, this study investigated the knowledge and attitude on diabetes mellitus (DM) among residents of Jos metropolis, Plateau State, Nigeria.

\section{METHODOLOGY}

\section{Research Design}

The study was a descriptive cross sectional survey, designed to examine the knowledge and attitude on diabetes mellitus (DM) among residents of Jos metropolis, Plateau State, Nigeria.

\section{Description of the Study Area}

The study area is Jos metropolis and it comprises Jos North and Jos South Local Government Areas. The two local government councils emerged in 1991 after Jos Local Government 
reorganized into two local government councils, with an estimated population of 437,217 with 220,856 as male while 216,361 female according to the 2006 census (National Population Commission 2006). Beside other tribes or ethnic groups that came from other parts of the country as well as people from other countries, the predominant ethnic groups in the local government area are the Beroms, Anagutas and Afizere.

As a cosmopolitan Local Government, the area is known for its commercial activities, which include the concentration of both large and small-scale industries like, the Jos Flour Mills, Naraguta Leather works, Banks, Markets and numerous healthcare facilities including Jos University Teaching Hospital (JUTH), Plateau specialist hospital and Bingham University Teaching Hospital.

\section{Study Population}

The study population includes all adult residents of Jos Metropolis that are women and men aged 25 years and 45 years for the quantitative study (survey) while persons (men and women) of age 30 years and above to 80 years were included for the Qualitative study (Focus Group Discussion). In addition, all eligible respondents who agree to participate in the study were included

\section{Inclusion and Exclusion Criteria:}

The study included all adult residents of Jos Metropolis that are women and men aged 25 years and 45 years for the quantitative study (survey) while persons (men and women) of age 30 years and above to 80 years were included for the Qualitative study (Focus Group Discussion). In addition, all eligible respondents who agree to participate in the study were included

However, persons below the age of 18 years were excluded from the study. All eligible respondents who declined or refused to participate in the study were excluded.

\section{Scope of the Study}

The study was directed to respondents who are within the age range of below 25 years and above 45 years, any respondent who is outside this age range is excluded from the research study for not being a cohort of the study group.

\section{Limitation of the Study}

This study is limited to Jos metropolis Plateau State for data collection and not the entire state. The study also limits itself to knowledge and attitude of people towards diabetes mellitus and does not extend to other aspect of healthcare due to time constraints

\section{Sample Size Determination}

For an estimated population of greater than 10,000, the fisher's method for sample size determination was used. The minimum sample size for this study was 394. However, 420 respondents were selected for the study. 


\section{Sampling Techniques}

Stage 1: A multistage sampling technique was used for this study.

\section{Stage II}

Systematic sampling method was used to select the respondents from the respective wards/sections. The first ward/section was selected by simple random sampling through balloting methods.

\section{Data Collection/Instruments}

Data for the study were collected using a structured questionnaire. The questionnaires were designed to seek information on the respondent's socio-demographic characteristics, knowledge, attitude and practices influencing diabetes mellitus among adults aged 25 to 45 years in Jos metropolis Plateau state

\section{Pre-Testing of Collection Instruments}

Data collection instrument was pretested at Bukuru town, Jos South Local Government. This was to ensure the validity and reliability of the data collection tool. The pre-tested questionnaires were then analyzed and necessary modifications done.

\section{Methods of Data Analysis}

Inspection of the coded data was done to ensure coding accuracy after which the data was analyzed using statistical packages for social sciences (SPSS) version 21. Findings were presented in tables, frequencies and percentages. A bivariate analysis of the variables involved were done specifically, the independent variable (diabetes mellitus) was cross tabulated against the main dependent variable (knowledge of diabetes mellitus) in order to ascertain the effect of one upon the other.

\section{Ethical Clearance}

Approval to carry out the research was obtained from Plateau State Ministry of Health (MOH/MIS/202/VOL I/X). All participants were provided with clear information and asked if they would be willing to participate or not. Only those who were willing to participate were involved and written consent was obtained. All information obtained for the study was treated with utmost confidentiality and the names of the respondents were not required in order to ensure anonymity.

\section{RESULTS}

\section{Socio-Demographic Characteristics of the Respondents}

Table 1 indicates that male respondents were 185 (47.1\%) while female respondents had 208 representing (52.9\%). This implies that both male and female respondents were fully represented in the study. However, there were more female respondents than the male respondents. 
ISSN: 2689-9418

Volume 4, Issue 2, 2021 (pp. 26-37)

The age bracket of 36-45 were 167 (42.5\%), respondents between the ages of 26-35 years 121 (30.8\%), while those within 25 years and below are 48 representing (12.2\%) the variation which indicates that those within the ages of 25 years are not too prone to diabetes mellitus. Majority of the respondents were married, 272 (69.2\%), while 106 (26.9\%) were single, nine persons $(2.3 \%)$ were widows/widower, $3(0.76 \%)$ were separated and the other three $(0.76 \%)$ persons were divorced. This can be attributed to the fact that the majority of the respondents were within the age range 36-41years and above. It is therefore believed that most people of this age category were usually married, which is a true reflection in the variable indices of the respondents.

Religious affiliation of respondents, $266(67.7 \%)$ were of the Christian faith, while $126(32.1 \%)$ practiced Islam, and only one person $(0.3 \%)$ was identified as a Traditional worshiper.

Concerning the academic qualification of the respondents, $263(66.9 \%)$ respondents had tertiary education, these include graduates from universities, colleges, polytechnics and other higher institutions, $62(15.8 \%)$ were secondary school certificate holders, 40 (10.2\%) were PGD holders, while $12(3.1 \%)$ of the respondents posses other qualifications. The high percentage of respondents with tertiary education signifies the high level of awareness on diabetes as a nutritional disease hence the interest to participate in the study was relatively high with low prevalent rate.

Occupation as shown indicates that significant number of the respondents who participated were $135(34.4 \%)$ civil servants, closely followed were 124 (31.6\%), Others (including drivers, traders, motorcycle/tricycle riders), $59(15.0 \%)$ were students, $39(9.9 \%)$ were farmers, while artisans constitute $36(9.2 \%)$ of the participants. This implies that different categories of people in Jos metropolis were involved in the study, because diabetes mellitus is of public health importance in the society.

Table 1: Socio-Demographic Characteristics of Respondents

\begin{tabular}{|l|l|l|l|}
\hline SEX & Frequency & Percentage (\%) & \\
Male & 185 & $47.1 \%$ & \\
Female & 208 & $52.9 \%$ & \\
Total & $\mathbf{3 9 3}$ & $\mathbf{1 0 0 \%}$ & \\
\hline AGE & Male (F/P) & Female (F/P) & Total \\
Below 25 years & $20(5.1 \%)$ & $28(7.1 \%)$ & $48(12.2 \%)$ \\
$26-35$ & $58(14.8 \%)$ & $63(16.0 \%)$ & $121(30.8 \%)$ \\
$36-45$ & $75(19.1 \%)$ & $92(23.4 \%)$ & $167(42.5 \%)$ \\
46 and above & $32(8.1 \%)$ & $25(6.4 \%)$ & $57(14.5 \%)$ \\
Total & $\mathbf{1 8 5}(\mathbf{4 7 . 1 \%})$ & $\mathbf{2 0 8}(\mathbf{5 2 . 9 \% )}$ & $\mathbf{3 9 3}(\mathbf{1 0 0 \%})$ \\
\hline MARITAL STATUS & Male (F/P) & Female (F/P) & Total \\
Single & $54(13.7 \%)$ & $52(13.2 \%)$ & $106(26.9 \%)$ \\
Married & $127(32.3 \%)$ & $145(36.9 \%)$ & $272(69.2 \%)$ \\
Widow/widower & 0 & $9(2.3 \%)$ & $9(2.3 \%)$ \\
Separated & $1(0.25 \%)$ & $2(0.5 \%)$ & $3(0.76 \%)$ \\
Divorce & $3(0.76 \%)$ & 0 & $3(0.76 \%)$ \\
Total & $\mathbf{1 8 5}(\mathbf{4 7 . 1 \%})$ & $\mathbf{2 0 8}(\mathbf{5 2 . 9 \% )}$ & $\mathbf{3 9 3}(\mathbf{1 0 0 \%})$ \\
\hline
\end{tabular}


ISSN: 2689-9418

Volume 4, Issue 2, 2021 (pp. 26-37)

www.abjournals.org

\begin{tabular}{|l|c|c|c|}
\hline HIGHEST QUALIFICATION & Male (F/P) & Female (F/P) & \multicolumn{1}{l|}{ Total } \\
ACQUIRED & & & \\
No response & $1(0.25 \%)$ & $3(0.76 \%)$ & $4(1.0 \%)$ \\
Primary & $2(0.5 \%)$ & $10(2.5 \%)$ & $12(3 \%)$ \\
Secondary & $44(11.2 \%)$ & $18(4.6 \%)$ & $62(15.8 \%)$ \\
Tertiary & $111(28.2 \%)$ & $152(38.7 \%)$ & $263(66.9 \%)$ \\
PGD and above & $23(5.9 \%)$ & $17(4.3 \%)$ & $40(10.2 \%)$ \\
Others & $4(1.0 \%)$ & $8(2.0 \%)$ & $12(3.1 \%)$ \\
Total & $\mathbf{1 8 5}(\mathbf{4 7 . 1 \%})$ & $\mathbf{2 0 8}(\mathbf{5 2 . 9 \%})$ & $\mathbf{3 9 3}(\mathbf{1 0 0 \%})$ \\
\hline OCCUPATION & Male (F/P) & Female (F/P) & Total \\
Student & $17(4.3 \%)$ & $42(10.7 \%)$ & $59(15.0 \%)$ \\
Farmer & $21(5.3 \%)$ & $18(4.6 \%)$ & $39(9.9 \%)$ \\
Civil Servant & $64(16.3 \%)$ & $71(18.1 \%)$ & $135(34.4 \%)$ \\
Artisan & $28(7.1 \%)$ & $8(2.0 \%)$ & $36(9.2 \%)$ \\
Others & $55(14 \%)$ & $69(17.6 \%)$ & $124(31.6 \%)$ \\
Total & $\mathbf{1 8 5}(\mathbf{4 7 . 1 \%})$ & $\mathbf{2 0 8}(\mathbf{5 2 . 9 \%})$ & $\mathbf{3 9 3}(\mathbf{1 0 0} \%)$ \\
\hline
\end{tabular}

\section{Knowledge of People towards Diabetes Mellitus in Jos}

The main variable of interest is the relationship between knowledge of diabetes mellitus and prevention of the sickness. This shows that $94.8 \%$ of the respondents agreed that they were knowledgeable of diabetes mellitus and have ideas of the possible causes of diabetes. Majority of the respondents $(60.7 \%)$ agreed that diabetes is a genetic disease. Although (37\%) of the respondents disagreed that diabetes is a genetic disease. However, majority of the key informants supported this finding during FGD where they insisted that diabetes is not a communicable disease and it is not a genetic disease; 177 respondents $(29.8 \%)$ had moderate knowledge to diabetes mellitus, while $9(2.3 \%)$ had very low knowledge of the disease. This finding is supported by the majority of the Focus Group Discussion (FGD) where most of the participants rated the knowledge by residents of Jos metropolis as High. Although, 30 (7.6\%) of the respondents indicated Low and 9 persons (2.3\%) indicated Very Low (Table 2).

Table 2: Respondent's knowledge of Diabetes Mellitus

\begin{tabular}{lcc}
\hline Response & Frequency & Percentage (\%) \\
\hline Very High & 84 & $21.4 \%$ \\
High & 89 & $22.6 \%$ \\
Moderate & 177 & $29.8 \%$ \\
Low & 30 & $7.6 \%$ \\
Very Low & 9 & $2.3 \%$ \\
No response & 4 & $1.0 \%$ \\
Total & $\mathbf{3 9 3}$ & $\mathbf{1 0 0 \%}$ \\
\hline
\end{tabular}


ISSN: 2689-9418

Volume 4, Issue 2, 2021 (pp. 26-37)

The respondents 165 (52\%) indicated that they know about diabetes in school, $116(29.5 \%)$ indicated that they know about diabetes through family members, while $85(21.6 \%)$ of the respondents indicated that they know of diabetes through health facilities and $20(5.1 \%)$ indicated that they know about diabetes through the media such as radio, television and the internet (Table 3).

Table 3: Response of Respondent's Access to knowledge of Diabetes mellitus

\begin{tabular}{lcc}
\hline Response & Frequency & Percentage (\%) \\
\hline Through family members & 116 & $29.5 \%$ \\
In the school & 165 & $52 \%$ \\
Through health facilitates & 85 & $21.6 \%$ \\
From the media & 20 & $5.1 \%$ \\
No response & 7 & $1.8 \%$ \\
Total & $\mathbf{3 9 3}$ & $\mathbf{1 0 0 \%}$ \\
\hline
\end{tabular}

Table 4 shows that the majority of the respondents $(66.9 \%)$ indicated that diabetes is a nutritional disease. This view was supported by most of the key informants during FGD who stated that: "diabetes is caused due to poor nutritional habit". The table also shows that 125 (31.8\%) of the respondents indicated that diabetes is caused by too much sugar. All the FGD participants supported this view stating that: "diabetes is known as disease caused by too much consumption of sugar". This can also be attributed to the fact that diabetes is seen by most people as a disease caused by too much consumption of sugar and also referred to as 'chiwon shuga' in Hausa language. Other respondents stated that diabetes is "disease of the rich people". Further investigation on how diabetes can be caused shows that $93.8 \%$ of the respondents indicated that diabetes is caused by individual lifestyle.

Table 4: Distribution of Respondent's Knowledge on the Causes of Diabetes Mellitus

\begin{tabular}{lcc}
\hline Response & Frequency & Percentage (\%) \\
\hline A Disease caused by evil spirit & 1 & $0.25 \%$ \\
A disease caused by too much sugar & 125 & $31.8 \%$ \\
A nutritional disease & 263 & $66.9 \%$ \\
A communicable disease & 0 & $0 \%$ \\
No response & 4 & $1.0 \%$ \\
Total & $\mathbf{3 9 3}$ & $\mathbf{1 0 0 \%}$ \\
\hline
\end{tabular}

Table 5 shows that majority of the respondents 247 (62.8\%) indicated that people between the ages of forty to sixty years are more likely to contract diabetes, $28(7.1 \%)$ of the respondents indicated that aged people of seventy years and above are more likely to be diabetic. While 89 $(22.6 \%)$ of the respondents indicated that people of all age categories can contract diabetes mellitus. 
ISSN: 2689-9418

Volume 4, Issue 2, 2021 (pp. 26-37)

www.abjournals.org

Table 5: Respondent's view on the age grade that is more likely to have diabetes

\begin{tabular}{lcc}
\hline Response & Frequency & Percentage (\%) \\
\hline $10-15$ years & 8 & $2.0 \%$ \\
20-30 years & 13 & $3.3 \%$ \\
40-60 years & 247 & $62.8 \%$ \\
70 years and Above & 28 & $7.1 \%$ \\
Any Age & 89 & $22.6 \%$ \\
No response & 8 & $2.0 \%$ \\
Total & $\mathbf{3 9 3}$ & $\mathbf{1 0 0 \%}$ \\
\hline
\end{tabular}

Table 6 shows that $318(80.9 \%)$ of the respondents indicated that one of the common signs and symptoms of diabetes is constant urination, $48(12.2 \%)$ of the respondents indicated that sweat at night is a symptom of diabetes mellitus.

Table 6: Respondent's view on the Sign/Symptoms of Diabetes Mellitus

\begin{tabular}{lcc}
\hline Response & Frequency & Percentage (\%) \\
\hline Heavy weight & 20 & $5.1 \%$ \\
Sweat at night & 48 & $12.2 \%$ \\
Constant urination & 318 & $80.9 \%$ \\
Skin rashes & 1 & $0.3 \%$ \\
No response & 6 & $1.5 \%$ \\
Total & $\mathbf{3 9 3}$ & $\mathbf{1 0 0 \%}$ \\
\hline
\end{tabular}

\section{Attitudes of People towards Diabetes Mellitus Patients ibn Jos}

This section examined the attitudes of people towards diabetes mellitus patients in Jos Metropolis. Findings of this study indicated that the majority $97.7 \%$ of the respondents agreed that other members of the society do stigmatize diabetic patients as the disease is associated with lifestyle, genetics disease and some people even associate diabetes to evil spirit and caused by witchcraft. In addition, all the respondents during Focus Group Discussion reported that members of the society do challenge diabetic patients with isolation and stigmatization.

Table 7 shows that the majority of the respondents 175 (44.5\%) disagreed and $172(43.7 \%)$ of the respondents strongly disagreed that diabetic patients are isolated by other members of the society. Again, $119(30.1 \%)$ and $100(25.4 \%)$ of the participants disagreed and strongly disagreed that people with diabetes do not eat together with family, friends or other members of the society. However, $164(42.5 \%)$ of the respondents indicated that people with diabetes do not eat with other members of the society who are not diabetic. Some key informants during FGD also stated, "To avoid spreading the disease, a diabetic patient should not eat with people". Majority of the $278(70.7 \%)$ respondents agreed that diabetic patients should not share their clothes with other members of the society. This view was also supported by most of the FGD participants who stressed that diabetic patients should always ensure that they do not 
African Journal of Health, Nursing and Midwifery

ISSN: 2689-9418

Volume 4, Issue 2, 2021 (pp. 26-37)

www.abjournals.org

allow others members of the community to use their clothes. However, $46(11.7 \%)$ of the respondents strongly disagreed that diabetes cannot be transmitted through clothes.

Table 7: Distribution of Respondent's view on how People Relate with Diabetic Patients

\begin{tabular}{|c|c|c|c|c|c|c|}
\hline Response & $\begin{array}{c}\text { A } \\
\text { F }(\%)\end{array}$ & $\begin{array}{c}\text { SA } \\
\text { F }(\%)\end{array}$ & $\begin{array}{c}\text { D } \\
\text { F }(\%)\end{array}$ & $\begin{array}{c}\text { SD } \\
\text { F }(\%)\end{array}$ & $\begin{array}{c}\text { UN } \\
\text { F }(\%)\end{array}$ & Total \\
\hline Isolation & $11(2.8 \%)$ & $25(6.4 \%)$ & $175(44.5 \%)$ & $172(43.7 \%)$ & $10(2.5 \%)$ & $393(100 \%)$ \\
\hline $\begin{array}{l}\text { Eating together } \\
\text { with the patient }\end{array}$ & 0 & $167(42.5 \%)$ & $119(30.1 \%)$ & $100(25.4 \%)$ & $7(1.8 \%)$ & $393(100 \%)$ \\
\hline $\begin{array}{l}\text { Sharing clothes } \\
\text { with the patient }\end{array}$ & $278(70.7 \%)$ & $69(17.6 \%)$ & 0 & $46(11.7 \%)$ & 0 & $393(100 \%)$ \\
\hline Stigmatization & $249(63.4 \%)$ & $75(19.1 \%)$ & $31(7.9 \%)$ & $29(7.4 \%)$ & $9(2.3 \%)$ & $393(100 \%)$ \\
\hline Others & $40(10.2 \%)$ & $48(12.2 \%)$ & $301(76.6 \%)$ & $1(0.3 \%)$ & $3(0.7 \%)$ & $393(100 \%)$ \\
\hline
\end{tabular}

Table 8 shows that 209 (53.2\%) indicated that diabetes mellitus is a disease of the rich people. Report from key informants also revealed that all the respondents shared similar views that diabetes is a sickness of the rich people. Stating that, "diabetes is known as disease of the rich people"; that 122 (31.0\%) of the respondents indicated (Others), stating that anybody can suffer the disease regardless of their social or economic status.

Table 8: Distribution of Respondent's view on the Category of people that are more Prone to Diabetes Mellitus

\begin{tabular}{lcc}
\hline Response & Frequency & Percentage (\%) \\
\hline Poor people & 39 & $9.9 \%$ \\
Rich people & 209 & $53.2 \%$ \\
Less privileged & 8 & $2.0 \%$ \\
Inheritance & 10 & $2.5 \%$ \\
Others (anybody could contact) & 122 & $31.0 \%$ \\
No response & 5 & $1.3 \%$ \\
Total & $\mathbf{3 9 3}$ & $\mathbf{1 0 0 \%}$ \\
\hline
\end{tabular}

\section{DISCUSSION Of FINDINGS}

This study shows that there are several factors that may cause diabetes mellitus; prominent factors identified in this study include lifestyle, poor eating habit, and socioeconomic status of people. This corroborates with a study by James (2008) who observed that social behavioral influences like urbanization, efficient transportation networks, increase in sedentary life, 
ISSN: 2689-9418

Volume 4, Issue 2, 2021 (pp. 26-37)

www.abjournals.org

advent of modern technology, reliance on electronic transactions and internet based social connections, coupled with the growing consumption of conveniently prepared and readily available foods and beverages rich in poorly satiating calories cause diabetes mellitus. This was also supported by White et al. (2002) where they disclosed that social, behavioral, and lifestyle factors are associated with T2D, other factors including genetic factors (are fixed from birth and potentially exert their effects throughout life), and environmental exposures also cause diabetes mellitus.

The relationship between individual socioeconomic status, place of residence (settlement) and the prevalence of diabetes mellitus was revealed as most of the respondents in this study identified that people in urban settlement are more likely to suffer diabetes mellitus than people in the rural settlement. In the same vein, people of high socioeconomic status are more prone to diabetes than the poor people. This corroborated with a study by Chijioke et al. (2010), who observed that more than $95 \%$ of cases of diabetes in Nigeria are type 2 diabetes. Many cases of type 1 diabetes may die of acute complications, being misdiagnosed, or may not be presented to hospital due to poverty and lack of health insurance.

The knowledge of diabetes mellitus in Jos metropolis indicated that the majority of the respondents $(94.8 \%)$ agreed that they were knowledgeable of diabetes and have ideas of the causes of diabetes mellitus. Some of the causes of diabetes in Jos include excessive consumption of alcohol, too much consumption of sugar, lifestyle, genetic factors and so forth. This aligned the assessment finding by (WHO, 2012), which shows that. This view was supported by an FGD report where almost all participants stated that some of the causes of diabetes in Jos metropolis are lifestyle, poor eating habit, and excessive consumption of sugar and alcohol. To buttress this finding, Okolie et al. (2009), reported that. The implication is that when people are aware of the causes of a disease they tend to prevent themselves from contracting the disease. However, this study found that the majority of the respondents $(66.9 \%)$ indicated that there is poor awareness to the public on diabetes mellitus. Consequently, the poor knowledge of the disease leads to stigmatization of diabetic patients in Jos. The level of knowledge and awareness of the causes and prevention of diabetes mellitus will play a pivotal role in enhancing quality and effective healthy living of people in Jos metropolis.

Regarding the attitude of people towards diabetes mellitus patients, finding of this study further indicated that $(97.7 \%)$ respondents agreed that other members of the society stigmatize diabetic patients as they associate the disease to immoral lifestyle and some people even associate the disease to evil spirit and caused by evil spirit. Corroborating this finding, Ekpebegh et al. (2009) observed that in Nigeria and most of the developing economies, poverty, ignorance, attribution of symptoms to other myths, lack of tools and basic infrastructure and inadequate training of health workers are responsible for much of the failure to detect DM. They also increase the risk of misdiagnosis and late diagnosis such that the vast majority of patients are diagnosed late, at complication stages of the disease. A major challenge prevalent in subSaharan Africa is the health belief system of patients, with reliance on traditional, rather than on allopathic medicine. 


\section{RECOMMENDATIONS}

To reduce stigmatization, it is recommended that the government, community leaders and the hospital personnel in Jos should ensure that the public are enlightened on the causes of diabetes through the electronic and print media, especially radio and television.

The hospital management should ensure that the training is such that health professionals should have knowledge on nutrition and ability to counsel drug addicts and alcoholics through regular workshops and seminars on diabetes mellitus.

\section{CONCLUSION}

This study shows that most residents of Jos metropolis are knowledgeable of the causes of diabetes mellitus, and are aware of the health, social and economic implications of diabetes mellitus on individuals and the society, but some of the respondents have poor knowledge of disease due to poor health education and poor access to effective and efficient health facility. This has often led to improper information on the disease most especially on the aspect of nutrition and primary causes of diabetes, which has often led to poor healthcare, stigmatization and even death of most diabetic patients. In addition, the study identified stigmatization as one among the challenges that diabetic patients do face by other members of the society in Jos metropolis. Other obstacles were poor level of awareness of diabetes among the diabetic patients and the public, poor availability of healthcare facilities, and high poverty rate.

\section{Contributions of the Study to Knowledge}

This study has therefore made significant contributions to the knowledge and attitude of residents of Jos on diabetes mellitus as it established that:

1. Eating proper nutrition and maintaining a healthy lifestyle alone cannot prevent from suffering diabetes mellitus. Rather, individuals must engage in physical activities and regular medical checkup to be aware of their health status.

2. The cause of diabetes is not only limited to age, socioeconomic status, genetics, lifestyle but extends to other factors such as environment and poor knowledge of the disease which often leads to untimely death of diabetic patients.

3. Collaboration among the health professionals and community leaders could educate the public on lifestyle modification and proper nutrition, which can reduce the risk of contracting diabetes mellitus in the study area.

\section{Suggestion for Further Study}

The researcher suggests that more study regarding genetics and diabetes should be intensified with focus on patients below the ages of 35 years. 
ISSN: 2689-9418

Volume 4, Issue 2, 2021 (pp. 26-37)

www.abjournals.org

\section{Author Contribution}

DMG initiate the study concept and designed the study, OCM carried out data collection, UGE carried out analysis, ECO \& LNC supervised the data collection and analysis, UGE analyzed the data, UGE and ECO prepared the first manuscript draft, all authors read, reviewed and approved the data draft of the final manuscript.

\section{REFERENCES}

Chijioke, A., Adamu, A. N. and Makusidi, A. M. (2010). Mortality patterns among type 2 diabetes mellitus patients in Ilorin, Nigeria. JEMDSA 2010; 15

Ekpebegh, C. O., Iwuala, S. O., Fasanmade, O. A., Ogbera, A. O., Igumbor, E. and Ohwovoriole, A. E. (2009). Diabetes foot ulceration in a Nigerian hospital: in-hospital mortality in relation to the presenting demographic, clinical and laboratory features. Int Wound J., 6: 381-385

James, W. P. (2008). The epidemiology of obesity: the size of the problem. J Intern Med., 263:336-352

Langenberg, C., Sharp, S. J. and Franks, P. W. (2014). Gene-lifestyle interaction and type 2 diabetes: the EPIC interact case-cohort study. PLoS Med., 11:1001647.

Ntui, I., Udoh, A. E., Esiere, K. S., Essien, O. and Egbe, E. R. (2006) The Pattern of Dietary Habits and Glycemic Control of Diabetics in Eastern Nigeria. PJN, 5: 43-45

Okolie, V. U., Ehiemere, O. I., Ihenacho, N. P. and Kalu-Igew, I. N. (2009). Knowledge of diabetes management and control by diabetic patients at Federal Medical Center Umuahia, Abia State Nigeria. In J Med Sci., 1: 353-358

Park, Y. W., Zhu, S., Palaniappan, L., Heshka, S., Carnethon, M. R. and Heymsfield, S. B. (2003). The metabolic syndrome: prevalence and associated risk factor findings in the US population from the Third National Health and Nutrition Examination Survey, 19881994. Arch Intern Med 2003;163:427-436

Unachukwu, C. N., Young, E. E. and Uchenna, D. I. (2011). Self Blood Glucose Monitoring among Diabetic Patients in Port Harcourt, Nigeria. NAJD, 19: 19-20

White, I. R., Altmann, D. R. and Nanchahal, K. (2002). Alcohol consumption and mortality: modelling risks for men and women at different ages. BMJ, 325:191.

World Health Organisation (2012). Use of glycated haemoglobin in the diagnosis of diabetes mellitus. Abbreviated Report of a WHO Consultation. 2012. Available from: URL: http: //www.who.int/diabetes/publications/report-hba1c_2012.pdf

World Health Organization (2014). The Abuja Declaration: Ten years on. 2014. Available from: URL: http:// www.who.int/ healthsystems/publications/abuja10.pdf 